\title{
Two way Linear Search Algorithm
}

\author{
Nitin Arora \\ Women Institute of \\ Technology, Dehradun
}

\author{
Garima Bhasin \\ Women Institute of \\ Technology, Dehradun
}

\author{
Neha Sharma \\ Women Institute of \\ Technology, Dehradun
}

\begin{abstract}
Linear search is the basic search algorithm used in data structures. If is also called as sequential search. Linear search is used to find a particular element in an array. It is not compulsory to arrange an array in any order (Ascending or Descending) as in the case of binary search. Linear search starts by sequentially scanning the elements in the array and if the element has been found, if will display the particular element and the index value of that element in that array. In this paper we present a novel searching algorithm Two Way Linear Search, which modified version of linear search algorithm and is based on comparing the elements from both ends.We have also compared the Two Way Linear search algorithm with Linear Search Algorithm. We used MATLAB 8.0 for implementation and Analysis of CPU time taken by both the algorithms. We have checked the algorithms with input sequences of lengths $10000,50000,100000$, and 5000000.Result shows that Two Way Searching Algorithm is working well for all input values and it takes lesser time if the element to be search is after the middle of the array, otherwise it takes same time as in case of linear search.
\end{abstract}

\section{Keywords}

Searching, Algorithms, Linear Search, Two Way Linear Search.

\section{INTRODUCTION}

An iterator traverses sequentially the array from left to right. When it encounters an element which is equal to the key the search stops and the index of that element is returned. If the key is not present in the array the size of the array will be returned. Linear search is the basic search algorithm used in data structures [1]. If is also called as sequential search. Linear search is used to find a particular element in an array. It is not compulsory to arrange an array in any order (Ascending or Descending) as in the case of binary search. Linear search starts by sequentially scanning the elements in the array and if the element has been found, if will display the particular element and the index value of that element in that array[2][3].

Rest of the paper is organized as follows: section 2 describes the Related work in this we have discussed Linear search algorithm. Section 3 describes our new Two Way Linear Search algorithm. Proof of correctness for Two Way Linear Search is described in section 4 and comparison between Linear Search and Two Way Linear Search is described in section 5 . Followed by conclusion and future scope in section 6 , acknowledgement in section 7 and used references are described in section 8 .

\section{RELATED WORK}

Linear search is used to find a particular element in an array. It is not compulsory to arrange an array in any order (Ascending or Descending) as in the case of binary search. Linear search starts by sequentially scanning the elements in the array and if the element has been found, if will display the particular element and the index value of that element in that array[4].

If we declare an array of size 8 and we initialize the array with the values (either static or dynamic declaration of values). In that if we mention the particular element to be identified, then the two way linear search will start to search the array from the index 0 . If the value is found at its first position itself, then it will return the value. If the value is not found, the search will increment the index value by 1 and then check the element. This process continues till the element has been identified.

Algorithm LinearSearch(x, L, n)

Input: Array $\mathrm{L}$, value $\mathrm{x}$, and number $\mathrm{n}$ of elements in $\mathrm{L}$

Output: Position i, $0 \leq \mathrm{i}<\mathrm{n}$ such that $\mathrm{L}[\mathrm{i}]=\mathrm{x}$, or -1 if $\mathrm{x}$ does not belongs to $\mathrm{L}$

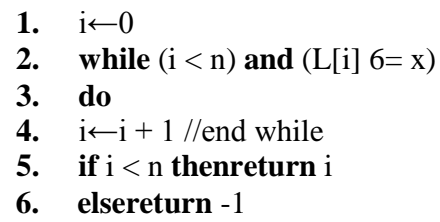

\section{TWO WAY LINEAR SEARCH ALGORITHM}

In Two Way Linear Search we initialize the array with the values (either static or dynamic declaration of values). In that if we mention the particular element to be identified, then the two way linear search will start to search the array from the index 0 as well as from the index $\mathrm{n}-1$. If the value is found at its position from the left or from the right, then it will return 1. If the values is not found the value returned is -1 .

\section{Algorithm TwoWayLinearSearch $(A$, num, $n)$}

Input: Array $\mathrm{A}$, value num to be search and $\mathrm{n}$ total number $\mathrm{n}$ elements in A

Output: 1 if num belongs to $\mathrm{A}$, or -1 if num does not belongs A
1. $\mathrm{p} \leftarrow 0$;
2. $\mathrm{q} \leftarrow \mathrm{n}-1$;
3. $\mathrm{a} \leftarrow 0$;
4. while $(\mathrm{p}<\mathrm{q})$
5. do
6. if $(\mathrm{L}[\mathrm{p}] \neq \mathrm{x}$ or $\mathrm{L}[\mathrm{q}] \neq \mathrm{x})$
7. then $p \leftarrow p+1 ; q \leftarrow q-1 ; a \leftarrow 0$;
8. else
9. then $\mathrm{a} \leftarrow 1$; //end while; 
10. if $\mathrm{a}==1$ return 1

11. elsereturn -1

\section{PROOF OF CORRECTNESS FOR TWO WAY LINEAR SEARCH}

To prove that an algorithm is correct, we need to show two things: (1) that the algorithm terminates, and (2) that it produces the correct output[5][6]

\subsection{Algorithm TwoWayLinearSearch terminates after a finite number of steps}

The variable $p$ takes value zero and the variable $q$ takes the values $n-1$, andafter each iterationof the while loop the value of $p$ increases by 1 and the value of $q$ decreases by 1 . If the while loopperformed an infinite number of iterations, however, this is not possible as one of the conditions of the while loop $\mathrm{p}<\mathrm{q}$. Thus the while loop will terminate as soon as $\mathrm{p}=\mathrm{q}$.

\subsection{Algorithm TwoWayLinearSearch produces the correct output}

In the second to last line the algorithm returns the value 1 . Note that this is the correctvalue to return since as the while loop ended and $\mathrm{a}=1$, this implies that $\mathrm{A}[\mathrm{]}=$ num.

\section{PERFORMANCE ANALYSIS AND COMPARISON}

Both the searching algorithms (Linear Search and Two Way Linear Search) were implemented in MATLAB 8.0 and tested for the input of length 10000,50000, 100000, and 5000000. Both the searching algorithms were executed on machine with 32-bit Operating System having Intel(R) Pentium (R) CPU P6200 @ $2.13 \mathrm{GHz}, 2.13 \mathrm{GHz}$ and installed memory (RAM) 3.00GB. The values of length of input and CPU time taken (msec) is shown in Table 1. Result shows that new Two Way Searching Algorithm is working well for all input values and it takes lesser time if the element to be search is after the middle of the array, otherwise it takes same time as in case of linear search.

Table 1. CPU Time (msec) for different lengths of input sequences

\begin{tabular}{|l|l|l|l|l|l|l|l|l|l|l|}
\hline \multirow{2}{*}{$\begin{array}{l}\text { Searching } \\
\text { Algorith } \\
\mathbf{m}\end{array}$} & \multicolumn{2}{|c|}{$\mathbf{1 0 0 0 0}$} & \multicolumn{2}{|c|}{$\mathbf{5 0 0 0}$} & \multicolumn{2}{c|}{$\mathbf{1 0 0 0 0 0}$} & \multicolumn{2}{c|}{$\mathbf{5 0 0 0 0 0}$} & \multicolumn{1}{|l|}{$\mathbf{1 0 0 0 0 0 0}$} \\
/Input & $\begin{array}{l}\text { present } \\
\text { at } \\
\text { starting } \\
\text { position }\end{array}$ & $\begin{array}{l}\text { Element } \\
\text { present } \\
\text { at } \\
\text { ending } \\
\text { position }\end{array}$ & $\begin{array}{l}\text { Element } \\
\text { present } \\
\text { at } \\
\text { starting } \\
\text { position }\end{array}$ & $\begin{array}{l}\text { Element } \\
\text { present } \\
\text { at } \\
\text { ending } \\
\text { position }\end{array}$ & $\begin{array}{l}\text { Element } \\
\text { present } \\
\text { at } \\
\text { starting } \\
\text { position }\end{array}$ & $\begin{array}{l}\text { Element } \\
\text { present } \\
\text { at } \\
\text { ending } \\
\text { position }\end{array}$ & $\begin{array}{l}\text { Element } \\
\text { present } \\
\text { at } \\
\text { starting } \\
\text { position }\end{array}$ & $\begin{array}{l}\text { Element } \\
\text { present } \\
\text { at } \\
\text { ending } \\
\text { position }\end{array}$ & $\begin{array}{l}\text { Element } \\
\text { present } \\
\text { at } \\
\text { starting } \\
\text { position }\end{array}$ & $\begin{array}{l}\text { Element } \\
\text { present } \\
\text { at } \\
\text { ending } \\
\text { position }\end{array}$ \\
\hline $\begin{array}{l}\text { Linear } \\
\text { Search }\end{array}$ & 0 & 0 & 0.0156 & 0.0160 & 0.0312 & 0.0614 & 0.0925 & 0.1125 & 0.1526 & 0.1714 \\
\hline $\begin{array}{l}\text { Two Way } \\
\text { Linear } \\
\text { Search }\end{array}$ & 0 & 0 & 0.0156 & 0 & 0.0312 & 0 & 0.0925 & 0.0154 & 0.1526 & 0.0317 \\
\hline
\end{tabular}

\section{CONCLUSION AND FUTURE SCOPE}

Searching is a technique that is used to find a particular element in an array. In Linear Search it is not compulsory to arrange an array in any order (Ascending or Descending) as in the case of binary search orderly. Result shows that new Two Way Searching Algorithm is working well for all input values and it takes lesser time if the element to be search is after the middle of the array, otherwise it takes same time as in case of linear search.

\section{ACKNOWLEDGEMENT}

This research paper is made possible through the help and support from everyone, including: Dr. Sandeep Goel (Director WIT), all the faculty members of Computer Science \& Engineering Department, all the students and friends. Especially, we would like to give extremely thanks to our family because without their support this work was not possible.

\section{REFERENCES}

[1] Arora, N., Tamta, V., and Kumar S. 2012. A Novel Sorting Algorithm and Comparison with Bubble Sort and Selection Sort. International Journal of Computer Applications. Vol 45. No 1.31-32

[2] Herbert Schildt Tata McGraw-Hill [2005], "The Complete Reference C fourth Edition".

[3] Alfred V., Aho J., Horroroft, Jeffrey D.U. (2002) Data Structures and Algorithms.
[4] Frank M.C. (2004) Data Abstraction and Problem Solving with C++. US: Pearson Education, Inc.

[5] Cormen T.H., Leiserson C.E., Rivest R.L. and Stein C. (2003) Introduction to Algorithms MIT Press, Cambridge, MA, 2nd edition.

[6] Seymour Lipschutz (2009) Data Structure with C, Schaum Series, Tata McGraw-Hill Education.

\section{ABOUT THE AUTHORS}

Nitin Arora received B. Tech. (Computer Science \& Engineering) from MNNIT Allahabad in 2008 and M. Tech. (Computer Science \& Engineering) from Govind Ballabh Pant Engineering College, Pauri, Garhwal, Uttarakhand in 2012. $\mathrm{He}$ is the member of IANEG (USA), ISOC (USA) and IACSIT (USA) and has published over several research papers in National and International journals/conferences in the field of Mobile Ad-Hoc Networks, Data Structures and Algorithms. He started his career as a Lecturer from Shobhit Institute of Engineering and Technology, Saharanpur and later on promoted as an Assistant Professor in the Department of Computer Science \& Engineering at Women Institute of Technology (WIT) Constituent college of Uttarakhand Technical University (UTU), Dehradun. He qualified National Eligibility Test (NET) in Computer \& Application in June-2012.

Garima Bhasin received Diploma in Computer Science \& Engineering from Government Polytechnic Dehradun and currently pursuing B. Tech in Computer Science \& Engineering from Women Institute of Technology, a 
Constituent College of Uttarakhand Technical University, Dehradun. Her area of interest includes C, C++, .Net, Java, Database and Data structures and Algorithms.

Neha Sharma received Diploma in Computer Science \& Engineering from Government Polytechnic Dehradun and currently pursuing B. Tech in Computer Science \& Engineering from Women Institute of Technology, a constituent Institute of Uttarakhand Technical University, Dehradun. Her area of interest includes Computer Networking, .NET and Java. 